\title{
Identifikasi Waste Pada Proses Produksi Key Set Clarinet Dengan Pendekatan Lean Manufacturing
}

\author{
Dana Marsetya Utama ${ }^{1}$, Shanty Kusuma Dewi ${ }^{2}$, Veronika Indah Mawarti ${ }^{3}$
}

\begin{abstract}
This study discusses lean manufacturing concept to identify waste in Key Set Clarinet production process at Yamaha Musical Products Indonesia, Ltd. The lean manufacturing concept is done intially by big picture mapping, waste assessment model (WAM), value stream mapping (VSM) and cause and effect diagram respectively. The results show that the dominant waste is defect (26.04\%), motion (19.34\%), inventory (19.22\%), and waiting (13.91\%).
\end{abstract}

Keywords. cause effect diagram, lean manufacturing, value stream mapping, waste assessment model.

Abstrak. Artikel ini menjelaskan pendekatan konsep manufaktur ramping untuk mengidentifikasi waste pada proses produksi Key Set Clarinet di PT. Yamaha Musical Products Indonesia. Pendekatan konsep manufaktur ramping dimulai dengan melakukan big picture mapping dilanjutkan dengan waste assessment model (WAM), value stream mapping (VSM) serta diagram sebab akibat. Hasil menunjukan bahwa waste dominan adalah cacat (26.04\%), pergerakan (19.34\%), persediaan (19.22\%), dan menunggu (13.91\%).

Kata kunci. diagram sebab akibat, manufaktur ramping, value stream mapping, waste assessment model.

\section{Pendahuluan}

Pada era globalisasi saat ini, persaingan dalam dunia industri menjadi semakin ketat dan kuat terutama pada perusahaan manufaktur. Oleh karena itu, suatu industri dituntut untuk selalu menjadi yang terdepan dalam persaingan industri agar tidak ditinggalkan oleh customer-nya. Hal ini membuat perusahaan manufaktur berlombalomba untuk memberikan layanan yang terbaik pada customer. Pada hakikatnya, perusahaan manufaktur menggunakan material yang cukup banyak dan tentunya hal ini akan mengakibatkan

\footnotetext{
${ }^{1}$ Dana Marsetiya Utama, Jurusan Teknik Industri, Fakultas Teknik, Universitas Muhammadiyah Malang Jl. Raya Tlogomas 246 Malang, Indonesia. (email:dana@umm.ac.id).

${ }^{2}$ Shanty Kusuma Dewi, Jurusan Teknik Industri, Fakultas Teknik, Universitas Muhammadiyah Malang Jl. Raya Tlogomas 246 Malang, Indonesia.

3 Veronika Indah Mawarti, Jurusan Teknik Industri, Fakultas Teknik, Universitas Muhammadiyah Malang Jl. Raya Tlogomas 246 Malang, Indonesia.
}

Diajukan: 19-02-2016

Disetujui: 16-06-2016 perusahaan tersebut mempunyai waste (pemborosan) yang tidak sedikit dalam proses produksi.Waste pada umunya terdiri dari tujuh jenis yaitu overproduction (produksi berlebihan), waiting (menunggu), motion (pergerakan), transportation (transportasi), unneccessary process (proses yang tidak perlu), inventory (persediaan) dan defect (cacat) (Hines \& Rich, 1997).

Penelitian dilakukan di PT. Yamaha Musical Products Indonesia (YMPI) yang berlokasi di Bangil, Jawa Timur, adalah sebuah perusahaan manufaktur yang memproduksi alat musik tiup di bawah naungan Yamaha Corporation Japan. Permasalahan yang dihadapi adalah tidak tercapainya target produksi Key Set Clarinet yang telah ditentukan oleh pihak Production Control. Total permintaan produksi selama 6 bulan mencapai 25,099 Key Set Clarinet, sedangkan aktual produksi hanya mencapai 23,960 Key Set Clarinet. Jumlah aktual produksi sudah termasuk kerja lembur (overtime) yang dilakukan pada hari Sabtu dan/atau Minggu. Oleh karena itu, perlu dilakukan optimalisasi pada sistem produksi Key Set Clarinet pada lini produksi Band Instrument Initial Process 2 untuk meningkatkan efisiensi dan efektivitas proses produksi.

Metode yang dapat digunakan perusahaan 
untuk mengatasi masalah yaitu dengan menggunakan konsep lean manufacturing. Secara terminologi lean berarti rangkaian aktivitas atau solusi untuk mengeliminasi waste, mereduksi operasi non-value added (NVA) dan meningkatkan operasi value added (VA) (Wee \& $\mathrm{Wu}, 2009)$. Lean manufacturing didefinisikan sebagai suatu pendekatan sistemik dan sistematik untuk mengidentifikasi dan menghilangkan pemborosan (waste) atau aktivitas-aktivitas yang tidak bernilai tambah (non-value adding activities) melalui peningkatan terus-menerus (radical continuous improvement) dengan cara mengalirkan produk (material, work-in-process, output) dari informasi menggunakan sistem tarik (pull system) dari internal dan eksternal untuk mengejar keunggulan dan kesempurnaan (Gaspersz \& Fontana, 2007). Sedangkan metode yang dibutuhkan untuk mengidentifikasi waste adalah dengan menggunakan waste assessment model (WAM) yang terdiri dari seven waste relationship (SWR), waste relationship matrix (WRM) dan waste assessment questionnaire (WAQ) (Rawabdeh, 2005). WAM mampu memberikan kontribusi untuk mencapai hasil yang akurat dalam mengidentifikasi waste (Mughni, 2012; Rochman, dkk., 2014). Oleh karena itu, pada penelitian ini akan dilakukan pendekatan konsep lean manufacturing yang diharapkan pada hasil akhirnya dapat mengidentifikasi waste yang paling dominan terhadap proses produksi, serta untuk meminimasi waste yang ada pada lini produksi Band Instrument Initial Process $2 \mathrm{Key}$ Set Clarinet di YMPI guna meningkatkan nilai tambah (value added).

\section{MetodoloGi}

Proses pengidentifikasian waste pada proses produksi Key Set Clarinet di YMPI dilakukan melalui tiga tahapan, yaitu: (1) value stream mapping dengan menggunakan big picture mapping, (2) WAM, dan (3) pemilihan detail mapping dengan value stream analysis tools (VALSAT).

Big picture mapping merupakan sebuah alat yang digunakan untuk menggambarkan suatu sistem secara keseluruhan beserta aliran nilai (value stream) yang terdapat di perusahaan (Hines \& Taylor, 2000). Sehingga nantinya diperoleh gambaran mengenai aliran informasi dan aliran fisik dari sistem yang ada, mengidentifikasi dimana terjadinya waste, serta menggambarkan lead time yang dibutuhkan dari masing-masing karakteristik proses yang terjadi.

WAM dimulai dengan mengungkapkan definisi dari setiap jenis waste, kemudian membentuk WRM yang mengklasifikasikan kekuatan waste relationship dengan menggunakan skala mulai dari sangat lemah hingga sangat kuat. Selanjutnya penggunaan WAQ yang digunakan untuk mengidentifikasi dan mengalokasikan waste yang terjadi pada lini produksi. Hal ini memungkinkan untuk menentukan peringkat waste dengan menggabungkan WRM dan hasil dari WAQ (Rawabdeh, 2005).

WAQ terdapat delapan tahapan perhitungan skor waste untuk mencapai hasil akhir berupa peringkat dari waste, yaitu sebagai berikut:

1) Mengelompokkan dan menghitung jumlah pertanyaan kuesioner berdasarkan jenis pertanyaan.

2) Melakukan pembobotan untuk tiap jenis waste pada tiap jenis pertanyaan kuesioner berdasarkan bobot dari WRM

3) Menghilangkan pengaruh variasi jumlah pertanyaan untuk tiap jenis pertanyaan dengan membagi bobot setiap baris dengan jumlah pertanyaan yang dikelompokkan $\left(N_{i}\right)$ untuk setiap pertanyaan dengan menggunakan persamaan berikut (Rawabdeh, 2005):

$$
S_{j}=\sum_{K=1}^{K} \frac{W_{j, K}}{N_{i}}
$$

dimana:

$S_{j}=$ skor waste

$W_{j}=$ bobot hubungan dari tiap jenis waste

$K=$ nomor pertanyaan (berkisar antara 1 sampai 68)

$N_{i}=$ jumlah pertanyaan yang dikelompokkan

4) Menghitung jumlah skor $\left(S_{j}\right)$ berdasarkan persamaan (1) dan frekuensi $\left(F_{j}\right)$ dari munculnya nilai pada tiap kolom waste dengan mengabaikan nilai 0 (nol)

5) Memasukkan nilai dari hasil kuesioner (nilai rata-rata jawaban) ke dalam tiap bobot nilai di tabel dengan menggunakan persamaan berikut:

$$
s_{j}=\sum_{K=1}^{K} X_{K} \times \frac{W_{j, K}}{N_{i}}
$$


dimana:

$s_{j}=$ total untuk nilai bobot waste

$X_{K}=$ nilai dari jawaban tiap pertanyaan kuesioner $(1,0.5$, atau 0$)$

6) Menghitung jumlah skor $\left(s_{j}\right)$ berdasarkan persamaan (2) dan frekuensi $\left(f_{j}\right)$ untuk tiap nilai bobot pada kolom waste.

7) Menghitung indikator awal untuk tiap waste $\left(Y_{j}\right)$ dengan menggunakan persamaan berikut:

$Y_{j}=\frac{s_{j}}{S_{j}} \times \frac{f_{j}}{F_{j}}$

dimana:

$Y_{j}=$ faktor indikasi awal dari setiap jenis waste

$f_{j}=$ frekuensi dari munculnya nilai pada tiap kolom waste dengan mengabaikan nilai 0 (nol) (frekuensi untuk $s_{j}$ )

$F_{j}=$ frekuensi dari munculnya nilai pada tiap kolom waste dengan mengabaikan nilai 0 (nol) (frekuensi untuk $S_{j}$ )

8) Menghitung nilai final waste factor $\left(Y_{\text {jfinal }}\right)$ dengan memasukkan faktor probabilitas pengaruh antara jenis waste $\left(P_{j}\right)$ berdasarkan total "from" dan "to" pada WRM. Kemudian memprosentasekan bentuk $Y_{\text {jfinal }}$ yang diperoleh sehingga bisa diketahui peringkat level dari masing-masing waste. $Y_{\text {jfinal }}$ dapat dihasilkan dengan menggunakan persamaan berikut:

$$
Y_{j}=Y_{j} \times P_{j}=\frac{s_{j}}{S_{j}} \times \frac{f_{j}}{F_{j}} \times P_{j}
$$

dimana:

$Y_{j}=$ faktor akhir dari setiap jenis waste

$P_{j}=$ probabilitas pengaruh antar jenis waste

Value stream analysis tool (VALSAT) digunakan dalam pemilihan detail mapping tool berdasarkan waste yang telah didefinisikan sebelumnya. Detail mapping ini merupakan pemetaan aliran nilai secara detail yang difokuskan pada value adding activity sehingga dapat diidentifikasikan waste yang terjadi serta penyebabnya. Terdapat tujuh macam detail mapping tool, diantaranya: (1) process activity mapping, (2) supply chain matrix, (3) production variety funnel, (4) quality filter mapping, (5) demand amplification mapping, (6) decision point analysis, dan (7) physical structure (Hines \& Rich, 1997).

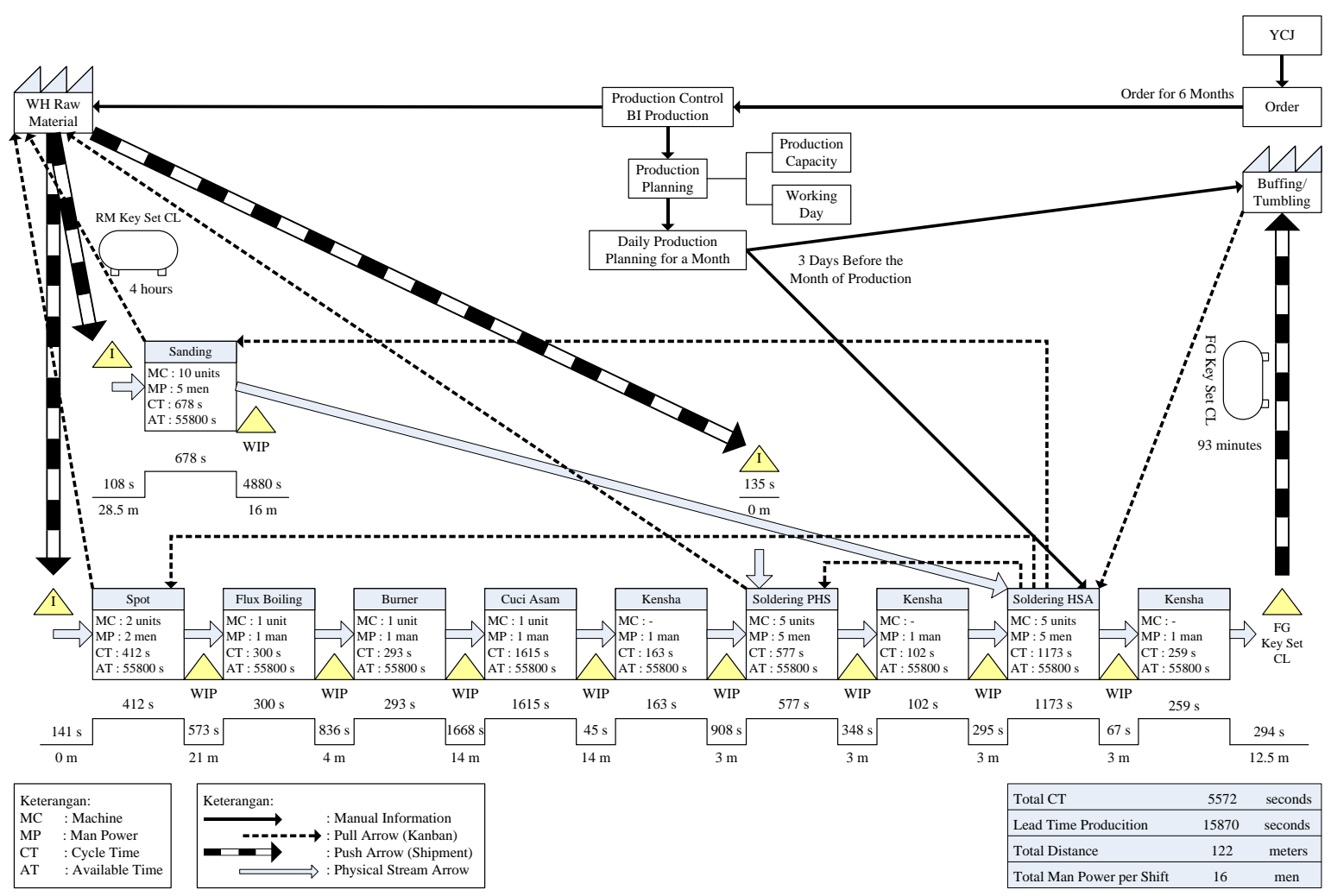

Gambar 1. Big picture mapping pada lini produksi Band Instrument Initial Process 2 Key Set Clarinet 


\section{HASIL DAN PEMBAHASAN}

Berdasarkan aliran informasi dan aliran fisik pada lini produksi Band Instrument Initial Process 2 Key Set Clarinet, maka dapat dibuat big picture mapping untuk memperoleh gambaran dimana waste yang terjadi, serta menggambarkan lead time yang dibutukan dari masing-masing karakteristik proses yang terjadi. Big picture mapping untuk lini produksi Band Instrument Initial Process 2 Key Set Clarinet dapat dilihat pada Gambar 1.

Gambar 1 menunjukan bahwa dalam memproduksi dua jenis key sekaligus (sebagai sample yaitu CL 250 Key 1A dan CL 250 Key 2A) yang dilakukan oleh operator memiliki lead time yang sangat panjang dan work in process (WIP) yang cukup besar. Total lead time produksi sebesar 15,870 detik atau 4.4083 jam dan total jarak tempuh proses adalah 122 meter. Hal inilah yang menyebabkan terdapat penumpukan material di store WIP, terutama saat menjelang jam kerja di tiap shift akan berakhir dan juga menjadi penyebab tidak tercapainya target produksi.

\section{Seven waste relationship}

Perhitungan keterkaitan antar waste dilakukan secara diskusi dengan Ketua-ketua Kelompok lantai produksi Key Set Clarinet. Setelah tiap bobot ditotal, maka selanjutnya ditentukan tingkat keterkaitannya. Hasil dari skor dan tingkat keterkaitan antar waste pada proses produksi Key Set Clarinet dapat dilihat pada Tabel 1.

\section{Waste relationship matrix (WRM)}

Berdasarkan hasil perhitungan keterkaitan waste pada Tabel 1 di atas, maka dapat dibuat WRM proses produksi Key Set Clarinet yang dapat dilihat pada Tabel 2 dan waste matrix value pada Tabel 3.
Tabel 1. Tabulasi keterkaitan antar waste Key Set Clarinet

\begin{tabular}{|c|c|c|c|}
\hline No. & $\begin{array}{c}\text { Tipe } \\
\text { Pertanyaan }\end{array}$ & $\begin{array}{l}\text { Total } \\
\text { Skor }\end{array}$ & $\begin{array}{c}\text { Tingkat } \\
\text { Keterkaitan }\end{array}$ \\
\hline 1 & $\mathrm{O}-\mathrm{I}$ & 3 & $\mathrm{U}$ \\
\hline 2 & $\mathrm{O}-\mathrm{D}$ & 7 & $\mathrm{O}$ \\
\hline 3 & $\mathrm{O}-\mathrm{M}$ & 4 & $\mathrm{U}$ \\
\hline 4 & $\mathrm{O}-\mathrm{T}$ & 3 & $\mathrm{U}$ \\
\hline 5 & $\mathrm{O}-\mathrm{W}$ & 3 & $\mathrm{U}$ \\
\hline 6 & $\mathrm{I}-\mathrm{O}$ & 2 & $\mathrm{U}$ \\
\hline 7 & $\mathrm{I}-\mathrm{D}$ & 5 & $\mathrm{O}$ \\
\hline 8 & $\mathrm{I}-\mathrm{M}$ & 5 & $\mathrm{O}$ \\
\hline 9 & $\mathrm{I}-\mathrm{T}$ & 14 & $\mathrm{E}$ \\
\hline 10 & $\mathrm{D}-\mathrm{O}$ & 8 & $\mathrm{O}$ \\
\hline 11 & $\mathrm{D}-\mathrm{I}$ & 10 & I \\
\hline 12 & $\mathrm{D}-\mathrm{M}$ & 18 & A \\
\hline 13 & $\mathrm{D}-\mathrm{T}$ & 7 & $\mathrm{O}$ \\
\hline 14 & $\mathrm{D}-\mathrm{W}$ & 17 & A \\
\hline 15 & $\mathrm{M}-\mathrm{I}$ & 6 & $\mathrm{O}$ \\
\hline 16 & $M-D$ & 13 & $\mathrm{E}$ \\
\hline 17 & $\mathrm{M}-\mathrm{W}$ & 12 & I \\
\hline 18 & $\mathrm{M}-\mathrm{P}$ & 14 & $\mathrm{E}$ \\
\hline 19 & $\mathrm{~T}-\mathrm{O}$ & 2 & $\mathrm{U}$ \\
\hline 20 & $\mathrm{~T}-\mathrm{I}$ & 2 & $\mathrm{U}$ \\
\hline 21 & $\mathrm{~T}-\mathrm{D}$ & 2 & $\mathrm{U}$ \\
\hline 22 & $\mathrm{~T}-\mathrm{M}$ & 10 & I \\
\hline 23 & $\mathrm{~T}-\mathrm{W}$ & 4 & $\mathrm{U}$ \\
\hline 24 & $\mathrm{P}-\mathrm{O}$ & 4 & $\mathrm{U}$ \\
\hline 25 & $\mathrm{P}-\mathrm{I}$ & 9 & I \\
\hline 26 & $P-D$ & 10 & $\mathrm{I}$ \\
\hline 27 & $\mathrm{P}-\mathrm{M}$ & 11 & I \\
\hline 28 & $\mathrm{P}-\mathrm{W}$ & 12 & I \\
\hline 29 & $\mathrm{~W}-\mathrm{O}$ & 4 & $\mathrm{U}$ \\
\hline 30 & $\mathrm{~W}-\mathrm{I}$ & 13 & $\mathrm{E}$ \\
\hline 31 & $\mathrm{~W}-\mathrm{D}$ & 9 & $\mathrm{I}$ \\
\hline $\begin{array}{l}\text { Ketera } \\
A=\text { nil } \\
B=\text { nil } \\
C=\text { nil } \\
D=\text { nil } \\
E=\text { nil }\end{array}$ & $\begin{array}{l}\text { n: } \\
17-20 \text { (absolv } \\
13-16 \text { (especi } \\
-12 \text { (importa } \\
5-8 \text { (ordinary } \\
-4 \text { (unimport }\end{array}$ & $\begin{array}{l}\text { y neces } \\
\text { y impor } \\
\text { oseness }\end{array}$ & $\begin{array}{l}\text { ary) } \\
\text { int) }\end{array}$ \\
\hline
\end{tabular}


Tabel 2. Waste relationship matrix Key Set Clarinet

\begin{tabular}{cccccccc}
\hline $\mathbf{F} / \mathbf{T}$ & $\mathbf{O}$ & $\mathbf{I}$ & $\mathbf{D}$ & $\mathbf{M}$ & $\mathbf{T}$ & $\mathbf{P}$ & $\mathbf{W}$ \\
\hline $\mathbf{O}$ & $\mathrm{A}$ & $\mathrm{U}$ & $\mathrm{O}$ & $\mathrm{U}$ & $\mathrm{U}$ & $\mathrm{X}$ & $\mathrm{U}$ \\
\hline $\mathbf{I}$ & $\mathrm{U}$ & $\mathrm{A}$ & $\mathrm{O}$ & $\mathrm{O}$ & $\mathrm{E}$ & $\mathrm{X}$ & $\mathrm{X}$ \\
\hline $\mathbf{D}$ & $\mathrm{O}$ & $\mathrm{I}$ & $\mathrm{A}$ & $\mathrm{A}$ & $\mathrm{O}$ & $\mathrm{X}$ & $\mathrm{A}$ \\
\hline $\mathbf{M}$ & $\mathrm{X}$ & $\mathrm{O}$ & $\mathrm{E}$ & $\mathrm{A}$ & $\mathrm{X}$ & $\mathrm{I}$ & $\mathrm{E}$ \\
\hline $\mathbf{T}$ & $\mathrm{U}$ & $\mathrm{U}$ & $\mathrm{U}$ & $\mathrm{I}$ & $\mathrm{A}$ & $\mathrm{X}$ & $\mathrm{U}$ \\
\hline $\mathbf{P}$ & $\mathrm{U}$ & $\mathrm{I}$ & $\mathrm{I}$ & $\mathrm{I}$ & $\mathrm{X}$ & $\mathrm{A}$ & $\mathrm{I}$ \\
\hline $\mathbf{W}$ & $\mathrm{U}$ & $\mathrm{E}$ & $\mathrm{I}$ & $\mathrm{X}$ & $\mathrm{X}$ & $\mathrm{X}$ & $\mathrm{A}$ \\
\hline
\end{tabular}

Tabel 3. Waste matrix value Key Set Clarinet

\begin{tabular}{cccccccccc}
\hline F/T & $\mathbf{O}$ & $\mathbf{I}$ & $\mathbf{D}$ & $\mathbf{M}$ & $\mathbf{T}$ & $\mathbf{P}$ & $\mathbf{W}$ & Score & $\boldsymbol{\%}$ \\
\hline $\mathbf{O}$ & 10 & 2 & 4 & 2 & 2 & 0 & 2 & 22 & $\mathbf{1 0 . 1 8 5}$ \\
\hline $\mathbf{I}$ & 2 & 10 & 4 & 4 & 8 & 0 & 0 & 28 & $\mathbf{1 2 . 9 6 3}$ \\
\hline $\mathbf{D}$ & 4 & 6 & 10 & 10 & 4 & 0 & 10 & 44 & $\mathbf{2 0 . 3 7}$ \\
\hline $\mathbf{M}$ & 0 & 4 & 8 & 10 & 0 & 6 & 8 & 36 & $\mathbf{1 6 . 6 6 7}$ \\
\hline $\mathbf{T}$ & 2 & 2 & 2 & 6 & 10 & 0 & 2 & 24 & $\mathbf{1 1 . 1 1 1}$ \\
\hline $\mathbf{P}$ & 2 & 6 & 6 & 6 & 0 & 10 & 6 & 36 & $\mathbf{1 6 . 6 6 7}$ \\
\hline $\mathbf{W}$ & 2 & 8 & 6 & 0 & 0 & 0 & 10 & 26 & $\mathbf{1 2 . 0 3 7}$ \\
\hline Score & 22 & 38 & 40 & 38 & 24 & 16 & 38 & 216 & $\mathbf{1 0 0}$ \\
\hline $\boldsymbol{\%}$ & $\mathbf{1 0 . 1 8 5}$ & $\mathbf{1 7 . 5 9 3}$ & $\mathbf{1 8 . 5 1 8}$ & $\mathbf{1 7 . 5 9 3}$ & $\mathbf{1 1 . 1 1 1}$ & $\mathbf{7 . 4 0 7}$ & $\mathbf{1 7 . 5 9 3}$ & $\mathbf{1 0 0}$ & \\
\hline Based & & & & & & & & &
\end{tabular}

Based on A:10, E:8, I:6, O:4, U:2, and X:0

Tabel 4. Hasil akhir perhitungan waste assessment

\begin{tabular}{lccccccc}
\hline & $\mathbf{O}$ & $\mathbf{I}$ & $\mathbf{D}$ & $\mathbf{M}$ & $\mathbf{T}$ & $\mathbf{P}$ & W \\
\hline Skor $\left(\boldsymbol{Y}_{\boldsymbol{j}}\right)$ & 0.05633 & 0.07854 & 0.06414 & 0.06149 & 0.08568 & 0.02923 & 0.06123 \\
\hline $\boldsymbol{P}_{\boldsymbol{j}}$ Faktor & 103.734 & 228.058 & 377.212 & 293.223 & 123.454 & 123.452 & 211.767 \\
\hline Hasil Akhir $\left(\boldsymbol{Y}_{\boldsymbol{j}}\right.$ Final $)$ & 5.84 & 17.91 & 24.27 & 18.03 & 10.58 & 3.61 & 12.97 \\
\hline Hasil Akhir $(\boldsymbol{\%})$ & 6.27 & 19.22 & 26.04 & 19.34 & 11.35 & 3.87 & 13.91 \\
\hline Ranking & 6 & 3 & 1 & 2 & 5 & 7 & 4 \\
\hline
\end{tabular}

\section{Waste assessment questionnaire (WAQ)}

Nilai waste yang didapat dari WRM selanjutnya digunakan untuk penilaian awal WAQ berdasarkan jenis pertanyaan. Kuesioner assessment ini terdiri dari 68 pertanyaan. Perhitungan menggunakan Pers. (1), (2), (3), dan (4). Hasil perhitungan akhir waste assessment dapat dilihat pada Tabel 4. Berdasarkan tabel perhitungan di atas, maka dapat dilihat peringkat waste pada proses produksi Key Set Clarinet dalam bentuk grafik pada Gambar 2 .

Berdasarkan hasil yang ditunjukkan oleh Diagram Pareto di atas, maka dapat diambil empat jenis waste tertinggi berdasarkan prinsip $80 / 20$ yaitu $20 \%$ penyebab bertanggungjawab terhadap $80 \%$ masalah yang muncul atau sebaliknya. Mengacu pada prinsip 80/20, maka waste tertinggi yang diambil untuk kemudian 


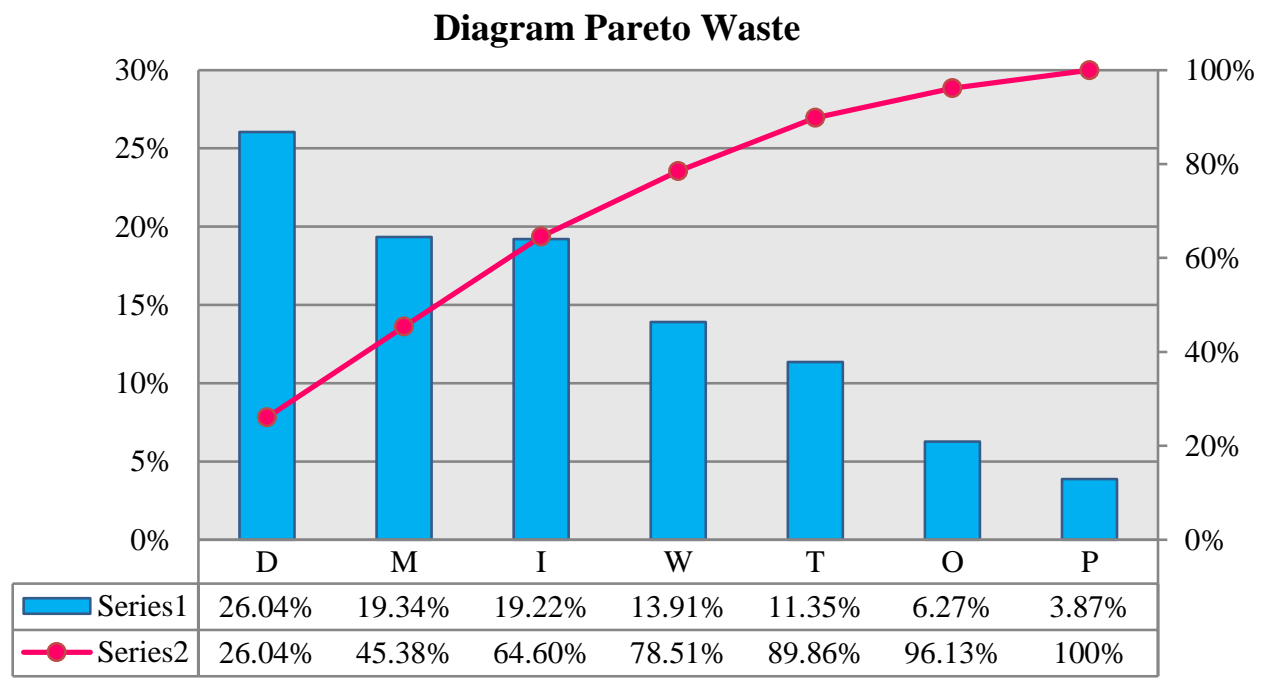

Gambar 2.Diagram Pareto waste

Tabel 5. Hasil pembobotan VALSAT

\begin{tabular}{ccccccccc}
\hline & & \multicolumn{7}{c}{ Mapping Tool } \\
\cline { 2 - 9 } Waste & Weight & $\begin{array}{c}\text { Process } \\
\text { Activity } \\
\text { Mapping }\end{array}$ & $\begin{array}{c}\text { Supply } \\
\text { Chain } \\
\text { Response } \\
\text { Matrix }\end{array}$ & $\begin{array}{c}\text { Production } \\
\text { Variety } \\
\text { Funnel }\end{array}$ & $\begin{array}{c}\text { Quality } \\
\text { Filter } \\
\text { Mapping }\end{array}$ & $\begin{array}{c}\text { Demand } \\
\text { Amplification } \\
\text { Mapping }\end{array}$ & $\begin{array}{c}\text { Decision } \\
\text { Point } \\
\text { Analysis }\end{array}$ & $\begin{array}{c}\text { Physical } \\
\text { Structure }\end{array}$ \\
\hline Overproduction & 6.27 & 6.27 & 18.81 & - & 6.27 & 18.81 & 18.81 & - \\
\hline Inventory & 19.22 & 57.66 & 172.98 & 57.66 & - & 172.98 & 57.66 & 19.22 \\
\hline Defect & 26.04 & 26.04 & - & - & 234.36 & - & - & - \\
\hline Motion & 19.34 & 174.06 & 19.34 & - & - & - & - & - \\
\hline Transportation & 11.35 & 102.15 & - & - & - & - & 3.87 & - \\
\hline $\begin{array}{c}\text { Unneccessary } \\
\text { Processing }\end{array}$ & 3.87 & 34.83 & - & 11.61 & 3.87 & - & 41.35 \\
\hline Waiting & 13.91 & 125.19 & 125.19 & 13.91 & - & 41.73 & 41.73 & - \\
\hline Total & & 526.2 & 336.32 & 83.18 & 244.5 & 233.52 & 122.07 & 30.57 \\
\hline
\end{tabular}

dianalisa yaitu defect, motion, inventory, dan waiting. Rekapan hasil Kuesioner di atas dijadikan sebagai acuan dalam pembobotan waste dalam pemilihan value stream analysis tools yang akan digunakan.

\section{Value stream analysis tools (VALSAT)}

Konsep VALSAT digunakan dalam pemilihan mapping tools dengan cara mengalikan hasil pembobotan waste dengan skala yang ada pada tabel VALSAT. Hasil pembobotan dengan menggunakan VALSAT tercantum pada Tabel 5. Berdasarkan hasil yang ditunjukkan oleh Tabel 5, maka terdapat tiga tools dengan bobot terbesar yang sesuai dengan jenis waste yang terjadi yang akan digunakan, yaitu process activity mapping (PAM), supply chain response matrix (SCRM), dan quality filter mapping (QFM).

\section{Process activity mapping (PAM)}

PAM digunakan untuk mengetahui proporsi dari kegiatan yang termasuk value added (VA), non-value added (NVA), dan non-value added but neccessary (NNVA). Hasil dari PAM pada lini produksi Band Instrument Initial Process 2 Key Set Clarinet dapat dilihat pada Tabel 6.

Berdasarkan hasil PAM di atas terdapat 129 jenis aktivitas dengan total waktu sebesar 15,870 detik atau 4.4083 jam untuk membuat dua jenis key yaitu CL 250 Key 1A dan CL 250 Key 2A. Detail prosentase perbandingan dari tiap jenis aktivitas pada proses produksi Key Set dapat dilihat pada Gambar 3. 
Tabel 6. Jumlah aktivitas proses produksi CL 250 Key $1 \mathrm{~A}$ dan $2 \mathrm{~A}$

\begin{tabular}{lcc}
\hline Aktivitas & Jumlah & Waktu (det) \\
\hline Operation & 30 & 5334 \\
\hline Transportation & 61 & 898 \\
\hline Inspection & 8 & 524 \\
\hline Storage & 1 & 0 \\
\hline Delay & 29 & 9114 \\
\hline Total & $\mathbf{1 2 9}$ & $\mathbf{1 5 8 7 0}$ \\
\hline
\end{tabular}

Tabel 7. Perbandingan waktu transportasi tiap proses

\begin{tabular}{lcc}
\hline Proses & Jumlah & Waktu (det) \\
\hline Sanding & 6 & 120 \\
\hline Spot & 7 & 104 \\
\hline Flux Boiling & 1 & 12 \\
\hline Burner & 10 & 44 \\
\hline Cuci Asam & 3 & 37 \\
\hline Soldering & 6 & 185 \\
\hline Kensha & 8 & 93 \\
\hline Total & $\mathbf{4 1}$ & $\mathbf{5 9 5}$ \\
\hline
\end{tabular}

Perbandingan Proses Tiap Aktivitas

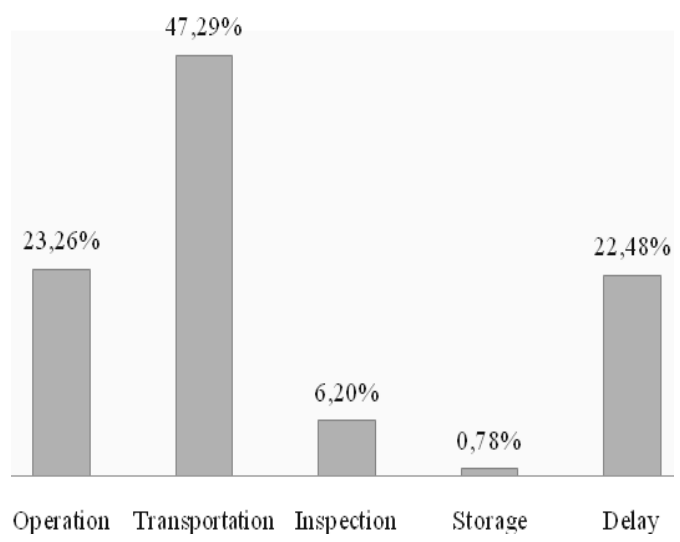

Gambar 3. Grafik Perbandingan Prosentase Tiap Aktivitas

Gambar 3 menunjukan bahwa aktivitas transportation merupakan jenis aktivitas yang paling mendominasi daripada aktivitas operation. Hal ini yang memicu terjadinya waste motion maupun waiting serta lead time yang tinggi di sepanjang aliran supply chain lantai produksi Key Set Clarinet karena tingginya jumlah aktivitas transportation yang mencapai dua kali lipat jumlah aktivitas operation. Perbandingan lama waktu yang dibutuhkan dalam aktivitas transportation pada keseluruhan proses dapat dilihat pada Tabel 7.

Aktivitas transportation tertinggi terjadi pada proses Soldering dan Sanding dengan akumulasi waktu masing-masing adalah 185 detik dan 120 detik. Untuk perbandingan antara aktivitas VA, NVA dan NNVA dari 129 aktivitas yang ada dapat dilihat pada Tabel 8.

Tabel 8. Prosentase PAM CL 250 Key 1A dan 2A

\begin{tabular}{lccc}
\hline Klasifikasi & Jumlah & $\begin{array}{c}\text { Waktu } \\
\text { (detik) }\end{array}$ & Prosentase \\
\hline VA & 26 & 5048 & $20.155 \%$ \\
\hline NVA & 25 & 8634 & $19.38 \%$ \\
\hline NNVA & 78 & 2188 & $60.465 \%$ \\
\hline Total & 129 & 15870 & $100 \%$ \\
\hline \multicolumn{2}{c}{ Value Ratio } & $\mathbf{0 . 2}$ \\
\hline
\end{tabular}

Berdasarkan perhitungan pada tabel 8, didapatkan hasil bahwa value ratio untuk proses produksi Key Set Clarinet seri CL 250 Key 1A dan 2A sebesar 0.2 yang menandakan bahwa terdapat pemborosan yang sangat tinggi. Sehingga 103 dari 129 aktivitas yang ada harus diminimalisir agar meningkatkan keefektifan dan keefesiensian yang dapat meningkatkan produktivitas pada lini produksi Band Instrument Initial Process 2 Key Set Clarinet.

\section{Supply chain response matrix (SCRM)}

SCRM digunakan untuk menggambarkan pola inventory dan lead time untuk memperkirakan jumlah inventory yang dibutuhkan dalam pemenuhan order dengan lead time yang tersedia. Penurunan inventory dan lead time merupakan penghematan value stream pada lini produksi.

Data yang dibutuhkan dalam pembuatan SCRM untuk mengetahui cumulative kedatangan raw material serta hasil produksi berupa WIP dan finished good pada lini produksi Band Instrument Initial Process $2 \mathrm{Key}$ Set Clarinet adalah sebagai berikut: (a) data penerimaan raw material per hari, (b) data input raw material dari area penyimpanan untuk diproses per hari, (c) data output produksi Key Set Clarinet per hari, dan (d) data pengiriman produk finished good Key Set Clarinet per hari. 
Tabel 9. Perhitungan SCRM Band InstrumentInitial Process 2 Key Set Clarinet

\begin{tabular}{llcccc}
\hline No & Item & $\begin{array}{l}\text { Days Physical } \\
\text { Stock }\end{array}$ & Lead Time & $\begin{array}{l}\text { Cummulative Days } \\
\text { Physical Stock }\end{array}$ & $\begin{array}{l}\text { Cummulative } \\
\text { Lead Time }\end{array}$ \\
\hline 1 & Stock raw material & 1.046 & 0.24 & 1.046 & 0.24 \\
2 & Stock WIP & 1.000 & 0.26 & 2.046 & 0.50 \\
3 & Stock finished good & 1.000 & 0.09 & 3.046 & 0.59 \\
\hline T O T A L & & & & $\mathbf{3 . 6 3 6}$ \\
\hline
\end{tabular}

Secara tabulasi perhitungan inventory dan lead time dapat dilihat pada Tabel 9 dengan total waktu dalam supply chain lini produksi Band Intrument Initial Process 2 Key Set Clarinet adalah 3.636 hari dengan kumulatif inventory sebesar 3.046 hari dan kumulatif lead time sebesar 0.59 hari.

Dari Tabel 9 dapat dilihat bahwa nilai days physical stock pada stock raw material memiliki nilai tertinggi yaitu 1.046 hari dibandingkan dengan stock WIP dan finished good yang bernilai 1 hari. Hal ini menandakan bahwa pada stock raw material memiliki waktu penyimpanan terlama karena penyimpanan raw material melebihi 1 hari.

Grafik perbandingan lead time antara inventory raw material, WIP, dan finished good dengan takt time inventory yang telah ditentukan pihak perusahaan, dapat dilihat pada Gambar 4.

\section{Perbandingan Lead Time Hasil Observasi dengan Takt Time Perusahaan}

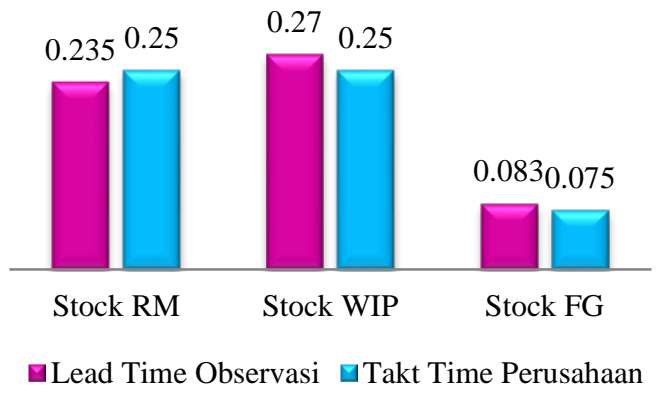

Gambar 4. Grafik perbandingan lead time inventory hasil observasi dengan takt time inventory

Berdasarkan gambar 4 dapat dilihat bahwa terjadi ketidaksesuaian antara lead time hasil observasi dengan takt time perusahaan. Pada stockraw material, lead time berada di bawah takt time yang menandakan pergerakan material lebih cepat dari waktu yang telah ditentukan. Pada stock WIP dan finished good, lead time berada di atas takt time yang menandakan pergerakan material lebih lambat dari waktu yang telah ditentukan. Hal ini dapat dikatakan bahwa pada stock WIP dan stock FG terdapat inventory berlebih yang seharusnya tidak melewati nilai dari takt time. Penyebab waste inventory ini dapat dilihat dari panjangnya lead time di tiap WIP yang tertera pada gambar big picture mapping yang berdampak pada jumlah inventory di lantai produksi. Pembengkakan inventory paling tinggi terjadi pada stock WIP dengan perbedaan nilai lead time sebesar 0.02 hari. Kondisi ini sangat sesuai dengan yang terjadi di lapangan yaitu dimana terjadi penumpukan WIP saat menjelang jam kerja tiap shift akan berakhir.

\section{Quality filter mapping (QFM)}

QFM digunakan sebagai tools untuk mengidentifikasi adanya masalah kualitas (cacat) yang terjadi sepanjang supply chain. Cacat yang akan digambarkan pada QFM disini yaitu cacat kualitas pada produk (reject part) yang ditemukan selama proses produksi. Hasil QFM terhadap lini produksi Band Instrument Initial Process 2 Key Set Clarinet dapat dilihat pada Gambar 5.

Berdasarkan QFM dapat dikatakan bahwa proses soldering merupakan proses yang memiliki jumlah reject part terbesar dan melebihi target yang telah ditentukan oleh perusahaan yaitu $0.37 \%$. Tidak hanya pada proses soldering, proses burner juga memiliki reject part yang melebihi dari target perusahaan. Masing-masing prosentase reject part dari proses soldering dan proses burner adalah $1.05 \%$ dan $0.64 \%$. Nilai prosentase ini belum termasuk dari reject part yang lolos dari proses kensha (inspeksi) sebesar $0.77 \%$. Reject part yang lolos hingga masuk ke proses berikutnya yaitu buffing/ tumbling akan 


\section{Perbandingan Aktual Reject Part dengan Target PT. YMPI}

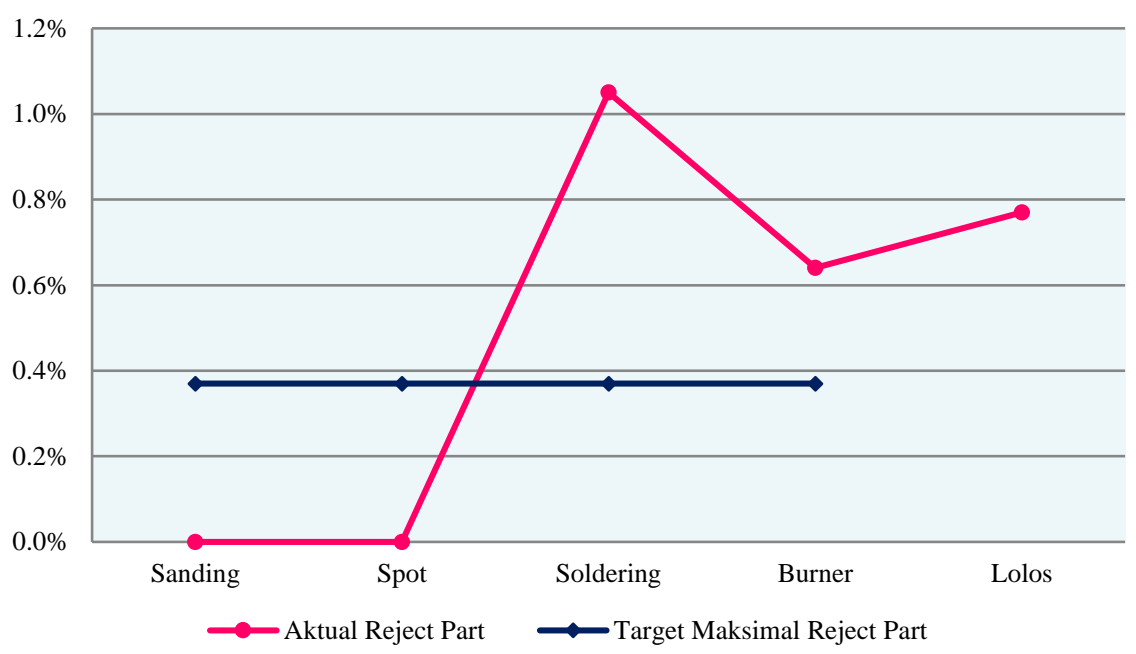

Gambar 5. Grafik perbandingan aktual reject part dengan target PT. YMPI

dikembalikan ke bagian kensha, agar diinspeksi ulang dan kemudian diperbaiki.

\section{Cause and effect diagram}

Analisa penyebab waste yang terjadi pada lini produksi Band Instrument Initial Process 2 Key Set Clarinet dilakukan dengan menggunakan cause and effect diagram. Cause and effect diagram dibuat berdasarkan hasil observasi dan diskusi dengan beberapa pihak di lantai produksi. Berikut dijabarkan mengenai analisa penyebab waste.

\section{Analisa Penyebab Waste Defect}

Cause and effect diagram dari waste defect terbesar yaitu pada proses soldering tersaji pada Gambar 6. Berdasarkan pada Gambar 6, penyebab utama terjadinya waste defect adalah dari faktor manpower dan management. Pada faktor manpower terdapat dua sebab, yaitu karena operator tidak konsentrasi saat melakukan proses Soldering yang menyebabkan pemasangan flux pada material menjadi kebanyakan sehingga material mengalami reject part berupa timah pada material terlalu banyak ataupun timah meluber. Penyebab kedua yaitu operator tidak mengikuti

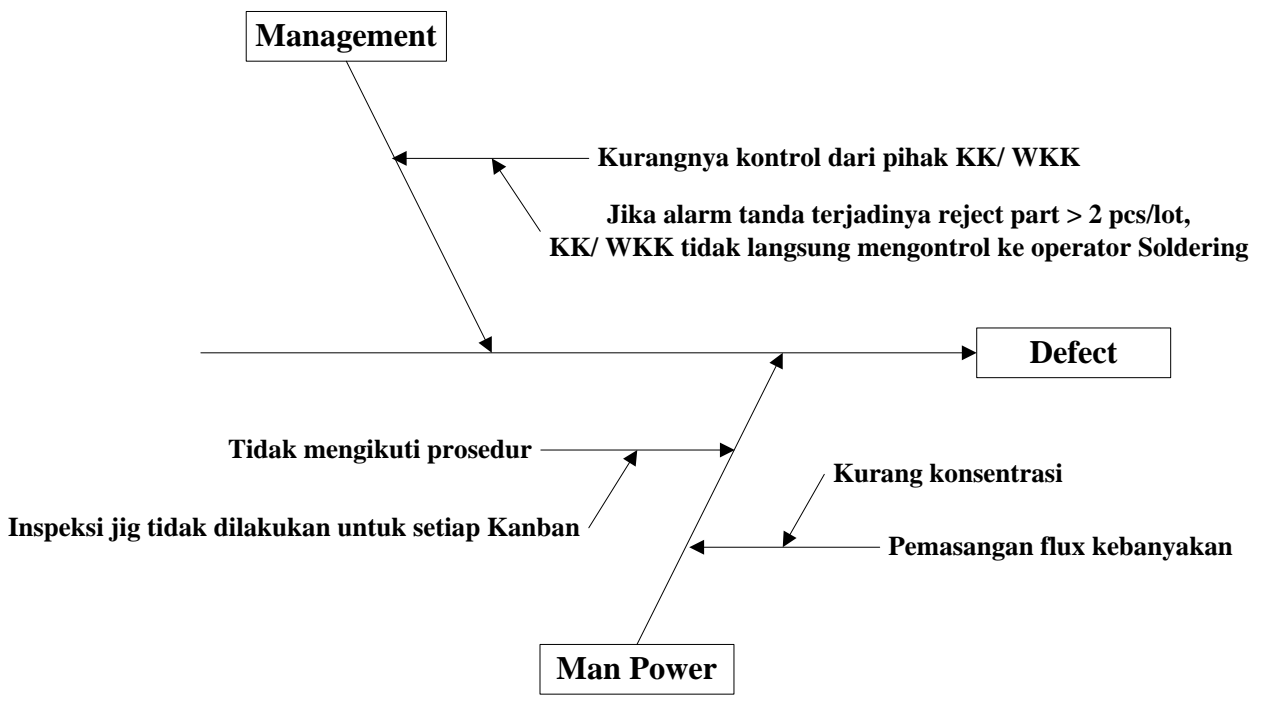

Gambar 6. Cause and effect diagram untuk waste defect 
prosedur standarisasi dengan melakukan inspeksi jig untuk setiap Kanban. Dalam melakukan proses soldering dibutuhkan konsentrasi dan ketelitian, karena proses ini memiliki tingkat kesulitan yang cukup tinggi. Oleh sebab itu jika operator tidak konsentrasi dan tidak teliti maka material yang diproses akan mengalami reject part.

Pada faktor management, disebabkan oleh kurangnya kontrol dari pihak KK/ WKK dalam mengawasi kinerja operator soldering. Pada saat alarm sebagai tanda peringatan dibunyikan oleh operator kensha yang menunjukkan terjadinya reject part melebihi 2 pcs/lot, pihak KK/ WKK terkadang mengabaikan alarm tersebut dan tidak segera mengontrol kinerja operator soldering. Hal ini mengakibatkan tingkat reject part tiap lot (satu Kanban) dari proses soldering menjadi semakin tinggi.

\section{Analisa penyebab waste motion dan waiting}

Cause and effect diagram dari waste motion dan waiting pada proses sanding dan soldering tersaji pada Gambar 7. Berdasarkan pada Gambar 7, penyebab utama terjadinya waste motion dan waiting adalah dari faktor manpower, method, management dan tool.

Pada faktor manpower dikarenakan operator Sanding berjalan terlalu santai ketika mengambil kanban di kanban central Sanding, mengambil raw material di rak store raw material, mengambil paper di lemari sanding, dan kemudian menuju mesin sanding yang sesuai dengan jenis material yang akan diproses. Aktivitas transportasi yang dilakukan oleh operator itu sendiri menimbulkan motion yang tidak memberikan nilai tambah dan berefek pada panjangnya lead time yang terjadi dalam proses sanding.

Pada faktor method, yaitu karena letak kanban central, rak store raw material, dan lemari yang menyimpan paper sanding diletakkan saling berjauhan yang menyebabkan operator sanding melakukan pergerakan yang sia-sia. Jarak yang ditempuh oleh operator sebelum melakukan proses sanding rata-rata mencapai 28,5 meter dalam sekali proses. Hal ini yang mendasari terjadinya waste motion yang tinggi pada proses sanding.

Pada faktor management, yaitu karena pihak manajemen tidak menggunakan Mizusumashi sebagai tranporter pada area sanding, sehingga berdampak besar terhadap keefektifan dan keefesiensian proses produksi. Pada faktor tool, yaitu karena operator soldering meminjam jig pada operator lain ketika akan melakukan inspeksi awal terhadap material yang sedang diproses sanding. Hal ini menyebabkan terjadinya waste motion dan waiting.

\section{Rekomendasi Perbaikan}

Dari hasil analisa yang telah dilakukan terhadap value stream mapping, process activity mapping, supply chain response matrix, quality

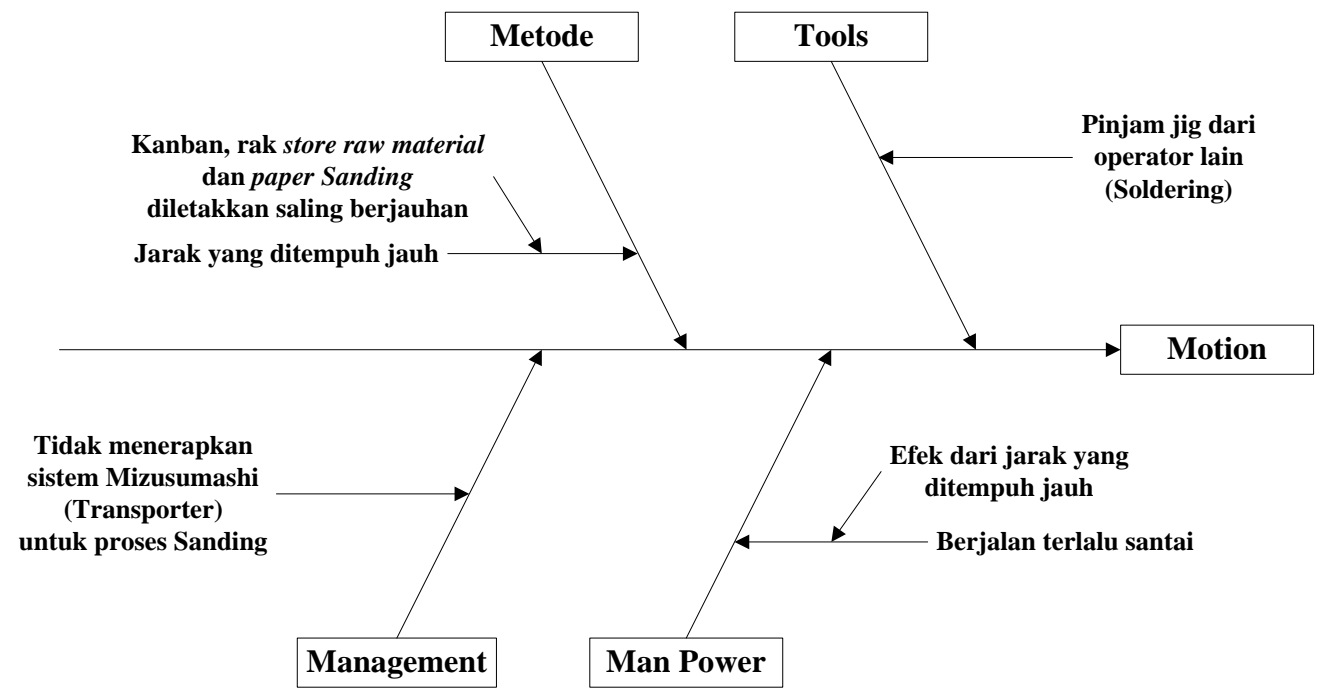

Gambar 7. Cause and effect diagram untuk waste motion dan waiting 
filtermapping, serta cause and effect diagram, maka akan dijadikan acuan sebagai pertimbangan mengenai rekomendasi perbaikan yang akan diberikan kepada YMPI agar dapat meminimasi waste yang terjadi pada lini produksi Band Instrument Initial Process 2 Key Set Clarinet. Rekomendasi perbaikan meliputi: pengarahan dari KK/ WKK kepada operator soldering untuk menjalankan proses produksi sesuai dengan standar operasional, penyediaan paper di sebelah mesin sanding, menggunakan Mizusumashi pada area sanding, menyediakan keranjang material lebih banyak disesuaikan dengan kebutuhan jumlah material, mengantar material yang telah diproses spot langsung oleh Mizusumashi (bukan oleh operator), merelokasi rak store Akabako berada diantara meja kensha Clarinet dan Flute, menyediakan kotak (wadah) untuk material yang telah diinspeksi lebih banyak, dan memaksimalkan fungsi Mizusumashi yang sebenarnya.

\section{SIMPULAN}

Permasalahan yang dihadapi oleh YMPI yaitu tidak tercapainya target produksi Key Set Clarinet yang telah ditentukan oleh pihak production control disebabkan adanya waste pada lini produksi Band Instrument Initial Process 2 Key Set Clarinet. Hasil identifikasi waste yang telah dilakukan dengan menggunakan metode WAM menghasilkan empat jenis waste yang paling dominan yaitu defect (26.04\%), motion (19.34\%), inventory (19.22\%), dan waiting (13.91\%).

\section{DAFTAR PUSTAKA}

Gaspersz, V.; Fontana, A. (2007). Lean Six Sigma for Manufacturing and Service Industries. Jakarta: PT Gramedia Pustaka Utama.

Hines, P.; Rich, N. (1997). 'The seven value stream mapping tools.' International Journal of Operations \& Production Management, Vol. 17 (1), pp. 46 - 64.

Mughni, A. (2012). Penaksiran waste pada proses produksi sepatu dengan waste relationship matrix. Prosiding Seminas Competitive Advantage II, Vol. 1 (2). Universitas Pesantren Tinggi Darul Ulum, Jombang. (akses online: http://www.journal.unipdu.ac.id/index.php/seminas/articl e/view/202/150)

Rawabdeh, I.A. (2005). 'A model for the assessment of waste in job shop environments.' International Journal of Operations \& Production Management, Vol. 25, pp. $800-822$.

Rochman, M.R.F.; Sugiono, S.; Efranto, R. Y. (2014). 'Penerapan lean manufacturing menggunakan WRM,
WAQ dan VALSAT untuk mengurangi waste pada proses finishing (Studi kasus di PT. Temprina Media Grafika Nganjuk).' Jurnal Rekayasa dan Manajemen Sistem Industri, Vol. 2, pp. 907 - 918.

Wee, H.; Wu, S. (2009). 'Lean supply chain and its effect on product cost and quality: a case study on Ford Motor Company'. Supply Chain Management: An International Journal, Vol. 14, pp.: $335-341$. 